\title{
InGaAs-Based High-Performance p-i-n Photodiodes
}

\author{
Ibrahim Kimukin, Student Member, IEEE, Necmi Biyikli, Student Member, IEEE, \\ Bayram Butun, Student Member, IEEE, Orhan Aytur, Member, IEEE, Selim M. Ünlü, Senior Member, IEEE, and \\ Ekmel Ozbay, Member, IEEE
}

\begin{abstract}
In this letter, we have designed, fabricated, and characterized high-speed and high-efficiency InGaAs-based p-i-n photodetectors with a resonant cavity enhanced structure. The devices were fabricated by a microwave-compatible process. By using a postprocess recess etch, we tuned the resonance wavelength from 1605 to $1558 \mathrm{~nm}$ while keeping the peak efficiencies above $60 \%$. The maximum quantum efficiency was $66 \%$ at $1572 \mathrm{~nm}$ which was in good agreement with our theoretical calculations. The photodiode had a linear response up to 6-mW optical power, where we obtained 5-mA photocurrent at 3-V reverse bias. The photodetector had a temporal response of 16 ps at 7-V bias. After system response deconvolution, the 3-dB bandwidth of the device was $31 \mathrm{GHz}$, which corresponds to a bandwidth-efficiency product of $20 \mathrm{GHz}$.
\end{abstract}

Index Terms-Bandwidth-efficiency, high speed, p-i-n photodiode, photodetector, resonant cavity enhanced.

\section{INTRODUCTION}

$\mathbf{H}$ IGH-PERFORMANCE photodetectors operating at $1.55-\mu \mathrm{m}$ wavelength are required for ultrafast photodetection in optical communication, measurement, and sampling systems. The photodetector performance is measured by the bandwidth-efficiency product (BWE) and is limited for conventional vertically illuminated photodetectors (VPDs) due to the bandwidth-efficiency tradeoff [1]. This tradeoff is due to the fact that the quantum efficiency and bandwidth of a conventional VPD have inverse dependencies on the photoabsorption layer thickness.

One detection scheme to overcome this limitation is edge-coupled photodiodes. This scheme has been used to achieve very high-speed metal-semiconductor-metal (MSM) [2] or p-i-n waveguide photodiodes with bandwidths above $500 \mathrm{GHz}$ [3], distributed MSM photodetectors with $78-\mathrm{GHz}$ bandwidth [4], avalanche photodiodes with $120-\mathrm{GHz}$ gain-bandwidth product [5], traveling-wave photodetectors with high output current [6] or 115-GHz bandwidth [7], and 110-GHz 50\% efficiency mushroom-mesa waveguide photodetectors [8]. The disadvantages of edge illuminated detectors are complex fabrication and integration along with difficult light coupling.

Manuscript received August 30, 2001; revised November 20, 2001. This work was supported by NATO under Grant SfP971970, by the National Science Foundation under Grant INT-9906220, and by the Turkish Department of Defense under Grant KOBRA-001 and Grant Thales JP8.04.

I. Kimukin and E. Ozbay are with the Department of Physics, Bilkent University, Bilkent, Ankara 06533, Turkey.

N. Biyikli, B. Butun, and O. Aytur are with the Department of Electrical Engineering, Bilkent University, Bilkent, Ankara 06533, Turkey.

S. M. Ünlü is with the Department of Electrical and Computer Engineering, Boston University, Boston, MA 02215 USA.

Publisher Item Identifier S 1041-1135(02)01219-3.
TABLE I

EPITAXIAL LAYER DESIGN OF THE RCE P-I-N PHOTODETECTOR

\begin{tabular}{|c|c|c|}
\hline Material & Thickness (nm) & Doping $\left(\mathrm{cm}^{-3}\right)$ \\
\hline InGaAs & 30 & $\mathrm{p}^{+} \quad 10^{19}$ \\
\hline Graded Layer & 30 & $10^{19}$ \\
\hline InAlAs & 210 & $10^{19}$ \\
\hline InAlAs & 50 & $\mathrm{n}-10^{16}$ \\
\hline Graded Layer & 30 & $n-\quad 10^{16}$ \\
\hline InGaAs & 300 & $n-\quad 10^{16}$ \\
\hline Graded Layer & 30 & $\mathrm{n}-\quad 10^{16}$ \\
\hline InAlAs & 60 & $n-\quad 10^{16}$ \\
\hline InAlAs & 300 & $n+3 \times 10^{18}$ \\
\hline InAlAs & 240 & None \\
\hline 25 Pair InAlAs/InAlGaAs DBR & $25 \times(121 / 112)$ & None \\
\hline InP Substrate & $600 \mu \mathrm{m}$ & Semi-insulating \\
\hline
\end{tabular}

The ease of fabrication, integration, and optical coupling makes the resonant cavity enhanced (RCE) photodiodes (PDs) attractive for high-performance photodetection [1], [9]-[12]. RCE-PD structure is formed by placing the conventional VPD inside a Fabry-Pérot resonant microcavity. The incident photons, which are at the resonance wavelength of the detector cavity are recycled, so that the quantum efficiency (QE) is enhanced at this wavelength. Therefore, by using RCE-PD with a thin active layer, high-efficiency values can be achieved without lowering the detector bandwidth [13], [14]. Using the RCE structure, InGaAs-based MSM PDs with 77\% QE and 10-GHz bandwidth at $1.3-\mu \mathrm{m}$ wavelength [15], Schotttky PDs with 55\% QE and 22.5-GHz bandwidth [16], p-i-n [17], and avalanche PDs with $\sim 70 \% \mathrm{QE}$ and $24 \mathrm{GHz}$ at unity gain [18] have been reported by other researchers. In this letter, we demonstrate a $1.55-\mu \mathrm{m}$ InGaAs-based high-performance and high output current RCE PD with a resonant wavelength tunable in $\sim 50-\mathrm{nm}$ range.

\section{DESIGN AND FABRICATION}

The epitaxial structure of the RCE p-i-n photodiode was designed using transfer-matrix-method based simulations. The layers were grown by molecular beam epitaxy on semi-insulating InP substrate. The bottom Bragg mirror (DBR) was made from quarter-wave stacks of InAlAs and $\operatorname{In}_{0.53} \mathrm{Al}_{0.13} \mathrm{Ga}_{0.34} \mathrm{As}$, designed for high reflectance at $1550-\mathrm{nm}$ center wavelength. $\mathrm{In}_{0.53} \mathrm{Al}_{0.13} \mathrm{Ga}_{0.34} \mathrm{As}$ was chosen to achieve high refractive index contrast with the lower index InAlAs without having any optical absorption in the distributed Bragg reflector (DBR) region. Theoretically, this DBR had a maximum reflectivity of $95 \%$ at $1550 \mathrm{~nm}$. All cavity layers except the 300-nm InGaAs absorption layer were transparent at the operation wavelengths. 
The details of the epitaxial structure are given in Table I. The comparison between the measured and simulated reflectance data of the as-grown wafer showed that the layers had been grown $4 \%$ thicker than the original design. This shifted the center wavelength of the DBR to $1610 \mathrm{~nm}$.

The devices were fabricated by a microwave-compatible process. Ohmic contacts to $\mathrm{n}^{+}$layers were formed by a phosphoric acid based etch that was followed by a self-aligned $\mathrm{Au}-\mathrm{Ge}-\mathrm{Ni}$ liftoff. The $\mathrm{p}^{+}$ohmic contact was achieved by $\mathrm{Au}-\mathrm{Ti}$ liftoff. The samples then were rapid thermal annealed at $400{ }^{\circ} \mathrm{C}$ for $1 \mathrm{~min}$. We etched away all the layers down to undoped InAlAs except the active areas using the isolation mask. Then Ti-Au interconnect metal was evaporated, which formed the coplanar waveguide (CPW) transmission lines on top of the undoped layer. The next step was deposition and patterning of 100-nm-thick $\mathrm{Si}_{3} \mathrm{~N}_{4}$ layer. Besides passivation, the $\mathrm{Si}_{3} \mathrm{~N}_{4}$ layer was also used as the dielectric of metal-insulator-metal bias capacitors. To reduce the parasitic capacitance, the $\mathrm{p}^{+}$ ohmic metal was connected to CPW pads by $0.7-\mu \mathrm{m}$-thick Ti-Au airbridge. The resulting RCE p-i-n photodiodes had breakdown voltages around $14 \mathrm{~V}$ and typical dark current densities were $10^{-5} \mathrm{~A} / \mathrm{cm}^{2}$ at $-1-\mathrm{V}$ bias.

\section{EXPERIMENTAL RESULTS}

Photoresponse measurements were carried out in the 1530-1630-nm range using a tunable laser source. The output of the laser was coupled to a single-mode fiber. The light was delivered to the devices by a lightwave fiber probe, and the electrical characterization was carried out on a microwave probe station. The top $\mathrm{p}^{+}$layers were recess etched in small steps, and the tuning of the resonance wavelength within the high reflectivity spectral region of the DBR was observed. Fig. 1(a) shows the spectral quantum efficiency measurements of a device under $5-\mathrm{V}$ reverse bias obtained by consecutive recess etches. Plot one is the quantum efficiency after the top InGaAs layer etch, while plots two-seven correspond to cumulative recess etches of $80,105,150,180,210$ and $240 \mathrm{~nm}$, respectively. The peak experimental quantum efficiency $30 \%$ of the as-grown sample at $1645 \mathrm{~nm}$ increases to $55 \%$ at $1614 \mathrm{~nm}$ after the first etch. The peak quantum efficiency increased up to $66 \%$ with tuning until the resonance wavelength reached $1572 \mathrm{~nm}$. This increase was due to the increase of the absorption coefficient of InGaAs at shorter wavelengths. As we continued the recess etch, the peak quantum efficiency decreased due to the decrease of the reflectivity of the Bragg mirror. The resonance wavelength was tuned for a total of $47 \mathrm{~nm}(1538-1605 \mathrm{~nm})$, while keeping the peak efficiencies above $60 \%$. The peak efficiency was above $50 \%$ for the resonant wavelengths between 1550 and $1620 \mathrm{~nm}$, corresponding to a tuning range of $70 \mathrm{~nm}$. Fig. 1(b) shows the quantum efficiency measurement and simulation results of the photodetector when the cavity resonance had been tuned to $1572 \mathrm{~nm}$. The difference between the simulation and the measurement can be explained with the $\pm 3 \%$ measurement error of the commercial photodiode that was used for calibration purposes [19]. The full-width at half-maximum (FWHM) of the devices was around $35 \mathrm{~nm}$. The quantum efficiency measurements were done at $5-\mathrm{V}$ reverse bias under $0.5-\mathrm{mW}$ optical

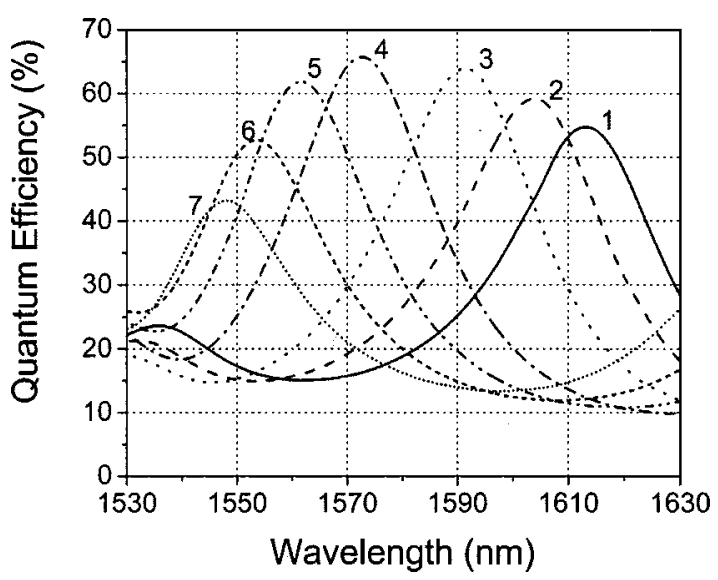

(a)

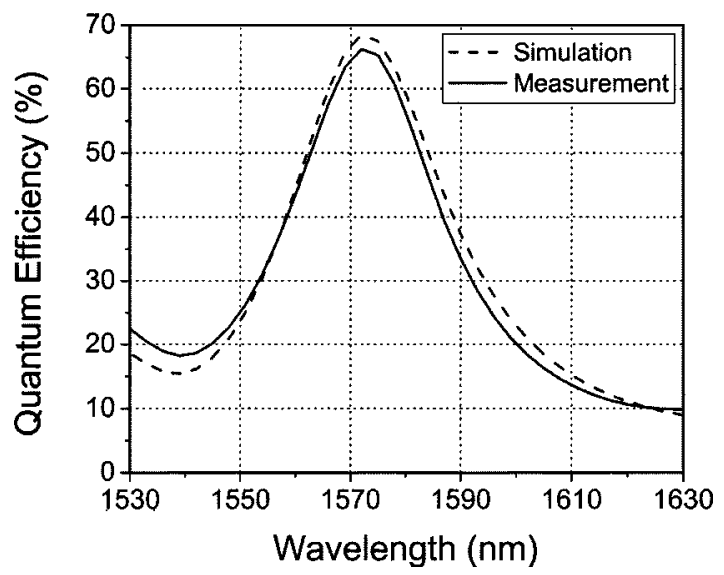

(b)

Fig. 1. (a) Spectral quantum efficiency measurements of the fabricated detectors after consecutive recess etches. (b) The theoretical calculation and experimental quantum efficiency measurement of a detector whose resonance had been tuned to $1572 \mathrm{~nm}$.

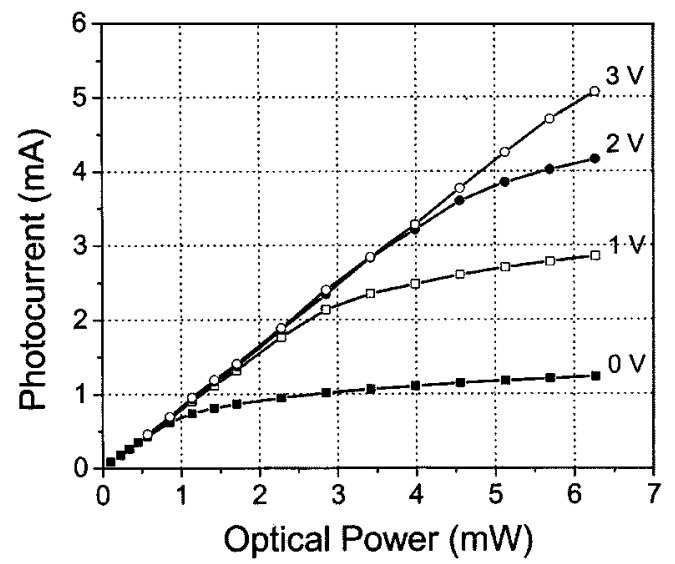

Fig. 2. Optical input power versus photocurrent of the photodetector under various reverse biases.

input power. When we increased the reverse bias beyond $3 \mathrm{~V}$, the active layer was fully depleted, and the quantum efficiency increased $6 \%$ with respect to zero bias. The responsivity of the PDs were also measured under various reverse biases up to 6-mW optical power, which was the maximum power that could be obtained from the laser. Fig. 2 shows the photocurrent versus input optical power at the resonance wavelength of $1572 \mathrm{~nm}$. Under $3 \mathrm{~V}$ and higher reverse biases, the PDs had 


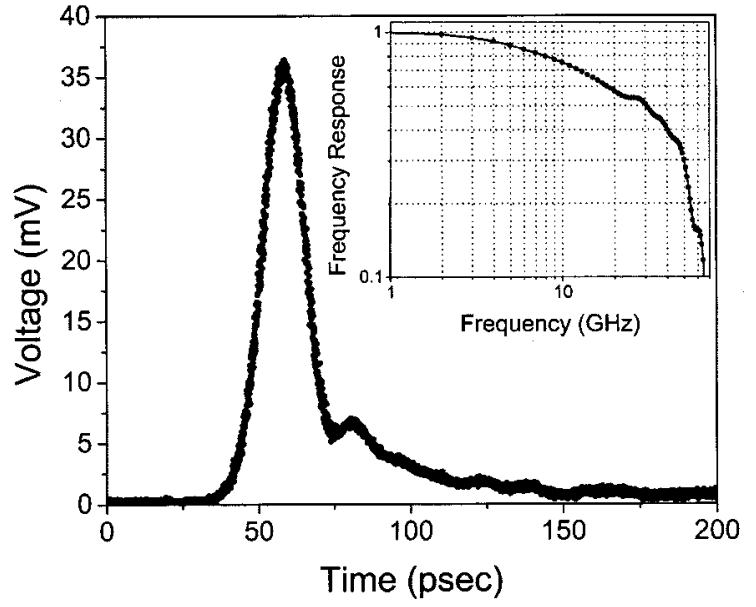

Fig. 3. Temporal response of the photodetector with a 16-ps FWHM. The inset shows the deconvolved frequency response obtained from the fast Fourier transform of the temporal detector response.

a linear photoresponse up to 6-mW optical power. At 6-mW optical power, the device exhibited a 5-mA photocurrent. The saturation was mainly due to the electric field screening caused by photogenerated carriers [20].

High-speed measurements were made with a picosecond fiber laser operating at $1550 \mathrm{~nm}$. The 1-ps FWHM optical pulses from the laser were coupled to the active area of the p-i-n photodiodes by means of a fiber probe. At zero bias, the response of the photodetectors had a long tail due to the diffusion of the carriers in the active layers. Measurements were done under bias to deplete the active layer completely and to get rid of the diffusion tail. Above 3-V reverse bias, we got a Gaussian response with a short tail. Fig. 3 shows the temporal response of a small area $\left(5 \times 5 \mu \mathrm{m}^{2}\right)$ photodetector measured at 7 -V bias by a $50-\mathrm{GHz}$ sampling scope. The photodiode output had a 16-ps FWHM. The measured data was corrected by deconvolving the effect of the 40-GHz bias-T. After the deconvolution, the device had a $3-\mathrm{dB}$ bandwidth of $31 \mathrm{GHz}$. Larger area devices $\left(80 \mu \mathrm{m}^{2}\right)$ also showed similar responses, which showed that the temporal response was limited by the transport of the photogenerated carriers. The measured bandwidth is lower than the theoretically predicted 3-dB bandwidth of $55 \mathrm{GHz}$ [21]. Although grading layers have been implemented to avoid carrier trapping, our measurement data shows that the device performance is still limited by the carrier trapping. In our devices, we used a digital grading that consisted of InP lattice-matched InGaAs-InAlAs layers. A linear grading may further improve the device performance.

\section{CONCLUSION}

We have demonstrated high-speed and high-efficiency resonant cavity enhanced (RCE) InGaAs-based p-i-n photodetectors. A peak quantum efficiency of $66 \%$ was measured along with $31-\mathrm{GHz}$ bandwidth, which corresponds to $20-\mathrm{GHz}$ bandwidth-efficiency product. The photoresponse was linear up to 6-mW optical power, where the devices exhibited 5-mA photocurrent.

\section{REFERENCES}

[1] S. M. Unlu and S. Strite, "Resonant cavity enhanced (RCE) photonic devices," J. Appl. Phys. Rev., vol. 78, no. 2, pp. 607-639, 1995.

[2] J.-W. Shi, K.-G. Gan, Y.-J. Chiu, C.-K. Sun, Y.-J. Yang, and J. E. Bowers, "Metal-semiconductor-metal traveling-wave photodetectors," IEEE Photon. Technol. Lett., vol. 16, pp. 623-625, June 2001.

[3] I.-H. Tan, C.-K. Sun, K. S. Giboney, J. E. Bowers, E. L. Hu, B. I. Miller, and R. J. Capik, "120-GHz long-wavelength low-capacitance photodetector with an air-bridge coplanar metal waveguide," IEEE Photon. Technol. Lett., vol. 7, pp. 1477-1479, Dec. 1995.

[4] E. Drödge, E. H. Böttcher, S. Kollakowski, A. Strittmatter, D. Bimberg, O. Riemann, and R. Steingrüber, "78 GHz InGaAs MSM photodetector," Electron. Lett., vol. 34, no. 23, pp. 2241-2243, 1998.

[5] G. S. Kinsey, C. C. Hansing, A. L. Holmes Jr, B. G. Streetman, J. C. Campbell, and A. G. Dentai, "Waveguide $\mathrm{In}_{0.53} \mathrm{Ga}_{0.47} \mathrm{As}-\mathrm{In}_{0.52}$ $\mathrm{Al}_{0.48} \mathrm{As}$ avalanche photodiode," IEEE Photon. Technol. Lett., vol. 12, pp. 416-418, Apr. 2000.

[6] S. Murthy, T. Jung, T. Chau, M. C. Wu, D. L. Sivco, and A. Y. Cho, "A novel monolithic distributed traveling-wave photodetector with parallel optical feed," IEEE Photon. Technol. Lett., vol. 12, pp. 681-683, June 2000.

[7] Y. Hirota, T. Hirono, T. Ishibashi, and H. Ito, "Traveling-wave photodetector for $1.55 \mu \mathrm{m}$ wavelength fabricated with unitraveling-carrier photodiodes," Appl. Phys. Lett., vol. 78, no. 24, pp. 3767-3769, 2001.

[8] K. Kato, A. Kozen, Y. Muramoto, Y. Itaya, T. Nagatsuma, and M. Yaita, "110 GHz 50\%-Efficiency mushroom-mesa waveguide p-i-n photodiode for a $1.55-\mu \mathrm{m}$ wavelength," IEEE Photon. Technol. Lett., vol. 6, pp. 719-721, June 1994.

[9] S. M. Unlu, K. Kishino, J. I. Chyi, L. Arsenault, J. Reed, and H. Morkoc, "Wavelength demultiplexing heterojunction phototransistor," Electron. Lett., vol. 26, no. 22, pp. 1857-1858, 1990.

[10] S. S. Murtaza, I. H. Tan, J. E. Bowers, E. H. Lu, K. A. Anselm, M. R. Islam, R. V. Chelakara, R. D. Dupuis, B. G. Streetman, and J. C. Campbell, "High-finesse resonant-cavity photodetectors with an adjustable resonance frequency," J. Lightwave Technol., vol. 14, pp. 1081-1089, June 1996.

[11] H. Nie, K. A. Anselm, C. Hu, S. S. Murtaza, B. G. Streetman, and J. C. Campbell, "High-speed resonant-cavity separate absorption and multiplication avalanche photodiodes with $130 \mathrm{GHz}$ gain-bandwidth product," Appl. Phys. Lett., vol. 70, no. 2, pp. 161-163, 1997.

[12] E. Ozbay, I. Kimukin, N. Biyikli, O. Aytur, M. Gokkavas, G. Ulu, S. M. Unlu, R. P. Mirin, K. A. Bertness, and D. H. Christensen, "Highspeed $>90 \%$ quantum efficiency $\mathrm{p}-\mathrm{i}-\mathrm{n}$ photodiodes with a resonance wavelength adjustable in the 795-835 nm range," Appl. Phys. Lett., vol. 74, no. 8, pp. 1072-1074, 1999.

[13] I. Kimukin, E. Ozbay, N. Biyikli, T. Kartaloglu, O. Aytur, S. M. Unlu, and G. Tuttle, "High-speed GaAs-based resonant-cavity-enhanced $1.3 \mu \mathrm{m}$ photodetector," Appl. Phys. Lett., vol. 77, no. 24, pp. 3890-3892, 2000.

[14] N. Biyikli, I. Kimukin, O. Aytur, M. Gokkavas, S. M. Unlu, and E. Ozbay, "45-GHz bandwidth-efficiency resonant-efficiency-enhanced ITO-Schottky photodiodes," IEEE Photon. Technol. Lett., vol. 13, pp. 705-707, July 2001.

[15] A. Strittmatter, S. Kollakowski, E. Drödge, E. H. Böttcher, and D. Bimberg, "High speed, high efficiency resonant-cavity enhanced InGaAs MSM photodetectors," Electron. Lett., vol. 32, no. 13, pp. 1231-1232, 1996.

[16] S. M. Spaziani, K. Vaccaro, and J. P. Lorenzo, "High-performance substrate-removal InGaAs Schottky photodetectors," IEEE Photon. Technol. Lett., vol. 10, pp. 1144-1146, Aug. 1998.

[17] S. Y. Hu, J. Ko, and L. A. Coldren, "Resonant-cavity InGaAs/InAl$\mathrm{GaAs} / \mathrm{InP}$ photodetector arrays for wavelength demultiplexing applications," Appl. Phys. Lett., vol. 70, no. 18, pp. 2347-2349, 1997.

[18] C. Lennox, H. Nie, P. Yuan, G. Kinsey, A. L. Holmes, B. G. Streetman, and J. C. Campbell, "Resonant-cavity InGaAs-InAlAs avalanche photodiodes with gain-bandwidth product of $290 \mathrm{GHz}$," IEEE Photon. Technol. Lett., vol. 11, pp. 1162-1164, Sept. 1999.

[19] Newport Online Catalog. 818 Series Cylindrical Detectors [Online]. Available: http://www.newport.com

[20] L. Y. Lin, M. C. Wu, T. Itoh, T. A. Vang, R. E. Muller, D. L. Sivco, and A. Y. Cho, "High-power high-speed photodetectors-design, analysis, and experimental demonstration," IEEE Trans. Microwave Theory. Technol., vol. 45, pp. 1320-1331, Aug. 1997.

[21] C. C. Barron, C. J. Mahon, B. J. Thibeault, G. Wang, W. Jiang, L. A. Coldren, and J. E. Bowers, "Resonant-cavity-enhanced pin photodetector with $17 \mathrm{GHz}$ bandwidth efficiency product," Electron. Lett., vol. 30, no. 21, pp. 1796-1797, 1994. 